\title{
DARWIN Y LA LAICIZACIÓN DEL DISCURSO SOBRE EL HOMBRE "
}

\author{
Patrick Tort
}

Director del Institut Charles Darwin International

\section{RESUMEN}

El resurgir de las teorizaciones anti-transformistas de horizonte creacionista sucede hoy en día a la moda sociobiológica de los dos decenios precedentes, como segunda fase del movimiento pendular que regula el retorno alternante de las ideologías más enfrentadas. El espectáculo de la polémica entre estas dos versiones tan mediatizadas de la reflexión sobre la vida, sus orígenes y su evolución se organiza como una lucha sin cuartel por la conquista de las conciencias. Este espectáculo nace en Estados Unidos, y se exporta. América no está ya, ni nunca lo ha estado, «entre la Biblia y Darwin». Al principio estuvo entre la Biblia y Spencer. Hoy, lógicamente, se encuentra entre el creacionismo y la sociobiología. La lectura de Darwin es actualmente un requisito previo para superar este juego de espejismos y falsas equivalencias.

\section{SUMMARY}

Resurging of the ideologies against transformism of a creationist orientation follows today the sociobiology fashion of the two precedent decades as second phase of the pendulous movement that regulates the alternating return of the faced ideologies. The show of the polemic among these two versions of the reflections on life, its origins and its evolution, is organized like a fight without barracks for the conquest of the consciences. This show is born in the United States and it is exported. America si not, neither he has never been, «between the Bible and Darwin». At the beginning it was between the Bible and Spencer. Today, logically, is between the Creationism and the Sociobiology. The reading of Darwin is, at the moment, a prerequisite to overcome this game of illusions and false equivalences.

A la luz de nuestros propios análisis y conceptos, expuestos en varias obras y principalmente en el Dictionnaire du darwinisme et de l'évolution, examinamos y explicamos aquí una vez más las razones teóricas e históricas por las cuales la obra de Darwin, generalmente ignorada tanto en su letra como en su lógica, ha sido y continúa siendo mal interpretada en su aspecto antroposociológico, dando así ocasión y fundamento a buen número de falsos debates contemporáneos.

\footnotetext{
* Traducido del francés por Carmen Martínez Oroz.
} 
Para demostrarlo es necesario volver sobre nuestros conceptos (expuestos por primera vez en 1983) de efecto reversivo de la evolución y de antropología darwiniana, y mostrar cómo constituyen una oposición a todo lo que un amplio consenso ideológico no instruido ha creído poder concluir en ciencias sociales de una versión travestida y esclerotizada de la teoría selectiva: «darwinismo social», maltusianismo, eugenismo, imperialismo, esclavismo, racismo «científico», neoliberalismo, desigualitarismo generalizado. La oposición «progresista» de ciertos representantes de estas mismas ciencias, crítica y acusadora respecto a un darwinismo mítico - falto de estudio- - ha extendido, por ignorancia y esquematización, partiendo de una reducción previa de Darwin a la vertiente eliminatoria de la teoría selectiva, la imagen de una doctrina culpable, sin ver operar el «cambio de sentido» que implica en Darwin el paso a la antropología «civilizada».

Opuestamente a esta imagen tenaz, la selección natural darwiniana de los instintos sociales y de sus consecuencias altruistas supera y reemplaza, en la historia de las sociedades humanas que emergen a la civilización, la de las ventajas biológicas, y funda sobre la base de un continuismo reversivo la primera genealogía materialista coherente de la moral.

\section{PREÁMBULO. DARWIN BAJO ANÁLISIS}

El estudio histórico-crítico de los mecanismos de aprehensión, de los procedimientos de interpretación y de los modos de conflictualización de los conocimientos científicos, en el seno de las redes de discurso que los designan como apuestas de un saber socialmente eficiente, constituye una parte importante de lo que hemos denominado en 1983 análisis de los complejos discursivos.

En el curso de aquel mismo año, abordando la ilustración de este propósito metodológico a partir del reexamen completo de una vertiente esencial del pensamiento moderno, deseamos que apareciese, a la luz de una demostración histórica y textual, el hecho de que la potencia de las apuestas ligadas a la recepción de la teoría darwinista en la conciencia científica, filosófica y política fuera tal que los conflictos de interpretación de los que ellas constituyeron el eje desembocaran en una representación globalmente falsa, o al menos, ilógicamente dividida entre la teoría de la selección y sus aplicaciones.

Desde entonces, se trataba, por una parte, de restablecer la integridad lógica de la teoría de Darwin sobre sus bases y, por otra, de explicar por qué no comprenderla ha sido durante tanto tiempo el único medio de parecer aceptarla. 


\section{LA REDUCCIÓN IDEOLÓGICA DEL DARWINISMO Y LA REITERACIÓN DEL ANTAGONIS- MO NATURALEZA / CULTURA}

Si en aquella época la comunidad científica, de acuerdo con la casi totalidad de los biólogos, admitía en su conjunto la validez del marco general - conceptos y método- del modelo darwiniano de explicación de las dinámicas evolutivas de los seres vivos (filogenia,variación-selección-divergencia, formación gradual de órganos complejos por acumulación de ventajas adaptativas, canalización del azar, integración de los datos de la genética y de la biología molecular en la teoría de la selección, equilibrios móviles de los ecosistemas, origen símico de la humanidad y diversificación geográfica de las razas humanas), el acuerdo se rompía cuando se trataba de pronunciarse sobre la legitimidad de extender la aplicación del «darwinismo» a la teorización del devenir reciente del hombre moderno, tomado en su historia y en sus realizaciones sociales. Lo «cultural» se oponía a la prosecución «natural» de un principio naturalista de explicación del ser que alcanzase a la especie que tiene la reputación de encarnar la culminación presente del proceso evolutivo de la naturaleza: el Hombre en la actualidad de su devenir.

Cada vez más netamente, las ciencias del hombre y de la sociedad nos daban a entender que la legitimidad de la pauta de interpretación darwiniana del devenir biológico en términos de competición-selección, es decir en términos de triunfo de los más aptos y eliminación de los menos aptos, se esfumaba ante la emergencia de una capacidad específica del Hombre social de organizar su devenir con medios no reducibles a los movilizados por su naturaleza estrictamente biológica. El gran conflicto reiterativo entre «naturaleza» y «cultura» o entre biología y sociedad volvía con una intensidad acrecentada por el progreso de las investigaciones desarrolladas en ciencias sociales desde la fundación durkheimiana de una disciplina que se había liberado, por la apropiación de su objeto, de la perspectiva unitaria y continuista de las sociologías biológicas, la mayor parte de las cuales se habían construido, por otra parte, a partir de una referencia, fundadora, a lo que habían percibido de la teoría biológica de Darwin.

Esta protesta de las ciencias sociales debía, pues, aplicando una lógica radical, constituir una argumentación contra el tema que aseguraba la coherencia de la de sus adversarios biólogos: la idea «naturalista» del continuum biológico-social. Para fundamentar un discontinuismo que pudiese garantizar la independencia de las ciencias sociales, cara a los esfuerzos anexionistas de la biología — y en particular desde 1975, de la «sociobiología» americana cuyo proyecto de hegemonía era explícito- antropólogos y sociólogos se empeñaron una vez más en hacer el recuento, cada cual según su formación y su escuela, de los rasgos de alteridad fundamental, que garantizaban que sus disciplinas tenían un objeto bien definido, protegido en su idiosincrasia por una ruptura que determinaba el paso (necesariamente un «salto») entre lo que pertenecía 
a las ciencias de la naturaleza y lo que, destacándose de éstas, había caído, sin posible vuelta atrás, bajo una nueva jurisdicción. Los operadores de ruptura invocados fueron múltiples y, sin embargo, en principio compatibles: invención de útiles y organización racional de la producción de los medios de existencia para unos, invención del lenguaje articulado para otros, prohibición del incesto o emergencia del pensamiento simbólico, todos ellos marcadores de singularidad específica que venían a sustituir, en el contexto de la modernidad científica, a la antigua signatura de la irreductibilidad humana, reivindicada a finales del siglo pasado: la ligada al sentimiento de los valores morales y a la religiosidad.

El discontinuismo progresista de las ciencias sociales se oponía así, por diversas vías globalmente homogeneizables, al continuismo totalitario de ciertos representantes de las ciencias biológicas que utilizando la autoridad del darwinismo, establecían el imperium de la naturaleza sobre la sociedad, y al mismo tiempo el de la biología sobre la política. La oposición ética no era ajena a este movimiento de resistencia al «biologicismo», y tomaba frecuentemente el tono de una exigencia de libertad del sujeto psicológico, comportamental, social e histórico, opuesto a la ofensiva de un pandeterminismo genético, seleccionista y reductor. Ésto explica, en el marco de la resistencia a la ola sociobiológica anglosajona, la complicidad que ha podido existir entre los representantes de las ciencias sociales, nacidos de la ruptura con un continuismo reduccionista de tipo espenceriano que encarnaba la filosofía biológico-social del liberalismo, y una porción cristiana del pensamiento biológico, como la representada en Francia por un naturalista como Pierre-Paul Grassé.

Las ciencias sociales, que emprendían así una lucha abierta por su propia supervivencia, adoptaban con ésto una actitud que las situaba en el riesgo de una inconsecuencia importante. Escoger el discontinuismo, además de la analogía con el gesto milenario de la teología, que reserva al Hombre un reino distinto del resto de la Creación, presentaba la dificultad del abandono de un materialismo, sin embargo mayoritariamente postulado por los representantes de las ciencias en cuestión como la misma condición de la cientificidad de su trabajo. En efecto, si nos atenemos al tronco común aceptado de las ideas-ejes del transformismo darwiniano, el Hombre pertenece evidentemente a la serie animal, de la cual porta la herencia biológica y comportamental a través de su evolución, y cualquiera que sea lo que esta evolución haya podido producir en él como divergencia pensable en términos de «superioridad»o «trascendencia evolutiva». Siendo precisamente Darwin quien convirtió en divisa transformista materialista (es decir en fórmula del continuismo genealógico) el antiguo adagio metafísico y fijista según el cual «la naturaleza no hace saltos» - lo que cada una a su nivel demuestran tanto la filogenia como la existencia misma de las especies vivientes-, contradecirlo volvía inevitablemente a reacreditar - aunque fuese a costa de artificios teóricos tales como el «salto cualitativo»—, una especie de fractura trascendente del orden genealógico, es decir continuista, de la naturaleza. 
A partir de entonces, se hizo fácil a los sociobiólogos retomar por su cuenta la actitud de Haeckel combatiendo a Weismann, y tachar de teólogos a los representantes de las ciencias sociales.

Por otra parte los partidarios de las ciencias sociales desarrollaban, algunos siguiendo al Marx de la carta a Engels de 1862, otros a un progresismo antropológico que ellos creían poder asociar a las conquistas positivas del estructuralismo, un antidarwinismo fundado sobre una reducción de todo el pensamiento darwiniano al ámbito estrictamente biológico circunscrito por Darwin en el Origen de las especies, obra en la que la resolución de no hablar del Hombre se expresa por un silencio de hecho.

Ambas categorías de interlocutores compartían pues la misma ignorancia (la de la antropología de Darwin tal como se enuncia en El origen del Hombre de 1871) y el mismo postulado que afirmaba la existencia doctrinal en Darwin de un pesado continuismo que reducía — para bien según unos, para mal según otros—el hombre social a un Hombre biológico, heredero directo de los instintos y conductas de sus ancestros simio-humanos, postulado éste deducido de un texto, El origen de las especies de 1859, donde el Hombre está temáticamente ausente ${ }^{1}$.

1 La evocación del Hombre aparece una sola vez — pero en tanto que objeto de estudios futurosen El origen de las especies. Es en el último capítulo, titulado «Recapitulaciones y conclusiones»: «Entreveo en un lejano porvenir abrirse campos de investigación aún más importantes. La psicología estará sólidamente basada sobre la fundación, ya bien establecida por el Sr. Herbert Spencer, de la necesidad de una adquisición gradual de cada facultad y aptitud mental; lo que proyectará una viva luz sobre el origen del Hombre y su historia». Una lectura no instruida de esta última frase consiste simplemente en caer en su trampa pensando que Darwin sigue los pasos de Spencer para elaborar la imagen de lo que debe ser el futuro de la ciencia del Hombre. Una lectura instruida escapa a la trampa descomponiéndola en motivos tácticos. Como mostramos a continuación y como lo declara sin discusión posible su Autobiografía, Darwin no simpatizaba con Spencer, ni con la persona ni con las ideas, que le parecían sin valor en el plano científico. Su alianza táctica con él concierne a la defensa general del transformismo (incluido el de Spencer en un sistema general de la evolución extraño a Darwin en tanto que construcción filosófica, incluyendo zonas de desacuerdo absoluto, tales como la filosofía social y la ética) en un contexto de lucha frontal contra el poder mantenido de la ideología conservadora en las instituciones científicas. En esta simple frase, Darwin, bajo la aprobación de una parte del pensamiento espenceriano (que examinará y discutirá a continuación), efectúa varias operaciones estratégicamente interesantes:

- se capta la benevolencia del representante de lo que está llamado a afirmarse como un sistema de pensamiento dominante en el cortejo ideológico que acompaña el desarrollo de la Inglaterra industrial;

— invoca una «ciencia del Hombre», en apoyo del transformismo, lo que le permite introducir con discreción el tema de una evolución del Hombre, que ha decidido no tratar, pero que quiere designar como tratable;

- señala que la mencionada ciencia establecerá que esta evolución es gradual (pues confirma su propio gradualismo en la representación global del proceso evolutivo);

- al mismo tiempo, hace ademán de remitirse a la psicología para tratar la cuestión de la evolución del Hombre, lo que le sitúa temporalmente al abrigo de toda sospecha de preparar sobre terreno naturalista una ofensiva de cara a la integración del Hombre en el esquema de conjunto de su teo- 
Si 1983 representa, a nuestros ojos, una fecha importante en la historia de la evolución de este conflicto, es porque es la de su disolución lógica en la elaboración del concepto de efecto reversivo de la evolución, que da la clave de la antropología darwiniana. Este concepto - nos permitimos decirlo hoy con un cierto alejamiento- ha jugado un papel esencial en la actualización contemporánea de los estudios darwinianos. Sin él, la resistencia intelectual a la ofensiva sociobiológica habría sido argumentada con menos potencia. Sin él (por que ha requerido, para su explicación y su recolocación en el contexto general de la obra y la historia, el rodeo enciclopédico), el Dictionnaire du darwinisme et de l'évolution no habría visto la luz. Sin él - y somos conscientes de que esta afirmación puede parecer exorbitante a los ojos de aquellos cuya órbita es precisamente monodisciplinar-, la antropología no podría constituirse en una disciplina articulable con las ciencias de la naturaleza. Sin él, las ciencias del hombre y de la sociedad en su conjunto continuarían postulando, a justo título, su autonomía, pero sin poderla fundamentar sobre un argumento que garantizase su necesidad. Sin él, la ética estaría abocada a una recaída periódica, manifiesta o larvada, en las morales de la obligación trascendente. Sin él, en fin, el materialismo, condición metodológica del conocimiento científico, quedaría sin consistencia en el ámbito de pensamiento dedicado a comprender la evolución del Hombre, las sociedades humanas y su historia.

Siempre hubo dos maneras de no comprender a Darwin. Ambas agotan en este campo las capacidades de la ideología. La primera, fue la de reducir para aplicar. La segunda, la de aplicar para reducir.

La primera de ellas - reducir para aplicar - fue la de la mayoría de los partidarios monistas de la teoría de la selección. Spencer, aunque lamarckiano, estuvo entre ellos. Creador de la filosofía evolucionista y de lo que más tarde se denominará «darwinismo social» - en el que hemos reconocido la primera forma moderna y sistematizada de «sociobiología»—, reduce el pensamiento de Darwin al núcleo teórico inicial (competición-eliminación) de la selección natural, retitulada «supervivencia del más apto», y lo aplica, no a la naturaleza, en la que continúa defendiendo predominantemente el adaptacionismo lamarckiano, sino a la sociedad humana.

[Primera regla de funcionamiento del trabajo de la ideología: la extensión del campo de aplicación de una teoría debe fundarse, primero, en su reducción a un fragmento o momento de sí misma, que será arbitrariamente privilegiado respecto a otros componentes de esa teoría capaces de indicar lo que serían, según su propia y total coherencia, sus aplicaciones legítimas.]

La segunda manera - aplicar para reducir - fue la de los adversarios dualistas y teólogos de la citada teoría: consiste en intentar demostrar que si el darwinismo fuese

ría. Lo que evidentemente hará en El origen del Hombre, pero en términos teóricos muy diferentes de los de Spencer, como se verá a continuación. 
cierto, el Hombre se reduciría a un animal, la sociedad sería un campo de batalla, la moral desaparecería bajo el egoísmo triunfante, los débiles serían eliminados sin recurso, lo que no podría ser. A otro nivel, el de la argumentación «científica», se ha dicho por ejemplo que si el darwinismo fuese cierto, los tiempos geológicos serían demasiado cortos para permitir la evolución gradual de las especies (Thomson, Jenkin, Mivart), la conservación de los estadios iniciales de las variaciones útiles no podría explicarse selectivamente (Mivart, Denton), el número de azares felices para conseguir un órgano complejo sería demasiado elevado (Mivart, Denton, Schützenberger). Siempre, se recurre a la aplicación mecánica de un principio simplificado para reducir la teoría a una inaplicabilidad de hecho. Pero podemos constatar que esta opción reposa sobre la misma reducción previa que preside la primera: se reduce la teoría de la variación (o la, moderna, de la mutación génica) a la idea de una transformación puntual aislada, cuyo destino no puede ser más que yuxtapositivo y unívocamente adicional. Se olvida la complejidad del organismo en su interactividad solidaria, para reducirlo a piezas separadas por abstracción matemática, a unidades fragmentarias susceptibles de ser cada una de ellas, el efecto de una causa y la causa de un efecto. Para negar lo que se cree conocer del «mecanismo» darwiniano, se pone en marcha una hipermecanización de las estructuras vivas en evolución ${ }^{2}$. Así pues, se trata siempre de reducir antes de aplicar, incluso si la aplicación está destinada a reducir.

\section{EQUIVALENCIA Y REPETICIONES}

No es de extrañar que estos dos discursos opuestos —el de los «partidarios» y el de los adversarios- digan lo mismo, la diferencia real entre ellos no es más que la axiológica, que distingue la aprobación de la reprobación. Cuando el teólogo dualista dice que si el darwinismo fuese cierto, la moral se reduciría al egoismo, y que los débiles serían eliminados, dice, contradiciendo a Spencer, lo mismo que Spencer, para quien toda moral debe edificarse sobre la base de un egoismo racionalizado, y para quien los débiles deben ser eliminados. Su punto de acuerdo se asienta sobre la proposición fundamental, idéntica, según la cual es legítimo deducir del darwinismo este tipo de consecuencia. Otro ejemplo de este mecanismo de equivalencia lógica de las proposiciones de base entre adversarios y partidarios declarados de una misma teoría es el del enfrentamiento entre Marx y los liberales sobre las implicaciones sociales del darwinismo. Los liberales de tipo spenceriano, reduciendo Darwin a Malthus, creían encontrar en Darwin el gran legitimador naturalista de la ley de hie-

2 Desarrollamos el análisis de este gesto clásico en nuestro estudio crítico sobre Vialleton, en TORT, P. (dir.), Pour Darwin, París, PUF, 1997, p. 597-668. 
rro del mercado y de la concurrencia social eliminatoria. En 1862, desdiciéndose de su primer entusiasmo materialista pro-darwinista, Marx escribe a Engels la célebre carta en la que reduce Darwin a Malthus y a la ideología economista liberal. Una vez más, si las dos actitudes se oponen como la aprobación a la crítica, la proposición central es la misma, y consiste en la afirmación de una reducción: la de Darwin a Malthus y a la ideología liberal victoriana.

[Segunda regla: una teoría aprobada por el adversario sólo debe ser combatida si se ha probado que el adversario la aprueba a justo título, y que saca consecuencias correctas de esta aprobación. En otras palabras, la aprobación del adversario condenará, a nuestos ojos, la teoría que aprueba, sólo si se demuestra que esta aprobación está fundada. Es aún preciso imponerse en cada caso la disciplina que consiste en hacer la hipótesis del contrario.]

El carácter repetitivo de este tipo de debate - ya se trate de la confrontación entre continuidad y ruptura en las relaciones naturaleza / cultura y biología / sociedad, ó del enfrentamiento entre partidarios y adversarios de Darwin como presunto legitimador del competitivismo eliminatorio- aparece como señal evidente de la impotencia para superarlo por medio de un avance por poco resolutivo que sea en el terreno de la ciencia.

[Tercera regla: la repetición estructural, incluso con desplazamiento de campo, de un debate teórico periódicamente resurgente en la historia de los complejos de discursos, manifiesta el hecho de que su componente ideológica permanece más fuerte que su productividad científica real. Un debate de contenido científico real se caracteriza, al contrario, por la producción de positividades o de nuevas cuestiones que impiden radicalmente su repetición idéntica.]

Así pues, nos corresponde una vez más demostrar en qué y cómo el concepto de efecto reversivo de la evolución permite romper esta recurrencia problemática, produciendo el elemento de positividad resolutiva que va a sustraer este tipo de debates del ámbito de la repetición ideológica. La conflictualización perpétuamente reconducida de los campos de representación asignados por los términos antagónicos de naturaleza y cultura aparecerá entonces como una apuesta ideológica, cuyo mantenimiento estará asegurado en tanto el concepto mismo de la evolución darwiniana no haya sido identificado y comprendido a través de sus verdaderas consecuencias antropológicas, que encierran en sí mismas la superación dinámica del conflicto.

NATURAL Y ARTIFICIAL: LA TEORÍA DEL APRENDIZAJE

COMO PRIMERA RESPUESTA AL ANTAGONISMO

Desde el Origen de las especies, el hecho de la variación, lejos de caracterizar solamente a los organismos como entidades biológicas individuales, concierne igual e 
idénticamente a sus instintos. Como las variaciones orgánicas, las variaciones instintivas son hereditarias, y están sometidas a la acción de la selección natural. Como ellas, pueden ser ventajosas ó no, en un contexto dado. Como ellas, son observables en la naturaleza, pero más fácilmente aún en el universo de la domesticación, en donde son efectivamente seleccionadas, de cara a una utilidad buscada por el seleccionador, lo que nos lleva a pensar que en la naturaleza son seleccionadas únicamente en función del beneficio del mismo organismo que las presenta.

Fiel al principio de economía del discurso teórico que siempre hemos defendido, y que se opone al narcisismo extracientífico de los que se creen en el deber de cambiar los términos de una demostración verificada, para extraer el beneficio retórico de una falsa novedad, retomaría aquí los desarrollos que hemos consagrado a la problemática darwiniana del aprendizaje, en el Dictionnaire du darwinisme, a la manera de un matemático, que no tiene ningún impedimento a la hora de reutilizar un compendio de razonamiento anteriormente comprobado, en el cuerpo de una explicación nueva.

En el capítulo VII del Origen de las especies, dedicado al instinto, y más precisamente en el curso del pasaje correspondiente al «cambio de hábitos hereditarios o de instintos en los animales domésticos», Darwin escribe:

\footnotetext{
«Se puede poner en duda que nadie hubiese soñado jamás adiestrar a los perros a la muestra, si alguno de estos animales no hubiese mostrado una tendencia natural hacia ese acto (...). El hecho de la muestra no es probablemente más que una exageración de la corta pausa durante la cual el animal se recoge antes de lanzarse sobre su presa. Una vez manifestada la primera tendencia a la muestra, la selección metódica, unida a los efectos hereditarios de un adiestramiento mantenido en cada generación sucesiva, han debido completar rápidamente la obra, colaborando al mismo tiempo al resultado la selección inconsciente, por el hecho de que cada cual procura naturalmente conseguir los perros que cazan y se comportan mejor, sin preocuparse por lo demás de la mejora de la raza».
}

Se puede elegir este fragmento como una buena introducción a la problemática darwiniana del aprendizaje, pues su desarrollo exhibe un estilo de pensamiento habitual en Darwin, tomado de la puesta a punto de la teoría de la selección, retomado y aplicado posteriormente para la interpretación en términos evolutivos del conjunto de fenómenos en los que se observa la intervención del Hombre en la naturaleza. Si intentamos espaciar los elementos de este pasaje para una mejor comprensión, es preciso hacerlo de la siguiente forma:

1. El «adiestramiento» es la prueba, en el universo «artificial» que se organiza alrededor de la cría de los animales domésticos, del carácter natural del aprendizaje, así como la variación bajo la influencia de la domesticación es la prueba de la variabilidad natural de los organismos, o como la selección artificial prueba la «seleccionabilidad» natural de los seres vivos. 
2. La selección (tanto natural como artificial) selecciona también instintos (sometidos estos últimos, al igual que los organismos, a variaciones). La selección de perros de caza que presentan una aptitud notable para la muestra, es una selección artificial (o una selección inconsciente) ejercida sobre variaciones del instinto animal ventajosas para el Hombre. Requiere pues el antecedente de la predisposición natural innata, según la regla enunciada por Darwin a propósito de la selección artificial, y que constata que el Hombre no crea, sino que orienta e intensifica la reproducción de ciertos caracteres en función de lo que la naturaleza propone a su elección.

3. El «adiestramiento» es lo que se añade a la selección —metódica o inconsciente- de los rasgos instintivos animales, ventajosos para el Hombre. Pero este añadido «artificial» se integra, según Darwin, a la herencia, es decir, inscribe en el patrimonio natural de las generaciones ciertas características comportamentales que, a partir de un soporte innato, han sido desarrolladas y reforzadas por aprendizaje. Dejemos de lado por el momento la cuestión del aspecto «lamarckiano» que puede conllevar esta idea, guardando en la memoria que esta concesión, lógica tratándose de una convicción extendida en su época, puede por lo general integrarse la mayor parte de las veces en una interpretación exclusivamente «darwiniana» en términos de selección de aptitudes.

Una vez expuestas estas premisas, es posible y fácil circunscribir la problemática del aprendizaje: como aptitud natural, se trata de un fenómeno universal —en los animales superiores, por supuesto, pues la investigación en un grado inferior de la escala animal está condenada a resultar demasiado interpretativa-, y ¿qué conclusiones pueden extraerse en el marco de la teoría de la descendencia con respecto al Hombre? ¿Cuál es exactamente la relación, en el marco de la evolución, del aprendizaje con el desarrollo de los instintos y el de la inteligencia? Estas cuestiones son tratadas en El origen del Hombre de 1871.

El aprendizaje y su universalidad

El problema de la universalidad de la capacidad de aprendizaje de los animales superiores es tratado, principalmente de una forma ilustrativa, en el capítulo III de $E l$ origen del Hombre, titulado «Comparaciones de las facultades mentales del Hombre con las de los animales inferiores» («inferiores» al Hombre, por supuesto, pero, haciendo abstracción de este último, superiores en la escala del Reino animal). Del mismo modo que los animales domésticos aprenden, a favor de la experiencia, a abstenerse de ingerir hierbas venenosas, los monos han aprendido probablemente a evitar los frutos venenosos de los Trópicos, al igual que han podido aprender a huir 
de las serpientes, desarrollando ese «terror» instintivo que parece caracterizarlos universalmente. Las aves de las islas oceánicas han aprendido a evitar al Hombre, pudiendo esta actitud inteligente «transformarse en instinto hereditario» después de generaciones de práctica. Los lobos criados por perros aprenden a ladrar. Ciertas aves pueden imitar el canto de aves de otras especies, e incluso palabras ó sonidos humanos. Un perro criado por una gata aprende a veces los gestos felinos del aseo, o los juegos de los gatitos. En numerosas especies animales, los padres enseñan a los hijos técnicas de caza y de captura. Los saltimbanquis han demostrado que es posible adiestrar a los monos a interpretar papeles en un espectáculo. Los perros de las regiones polares parecen haber aprendido a separarse unos de otros cuando el tiro de su trineo pasa sobre una capa delgada de hielo. Un lucio, condicionado por la repetición de un choque frontal contra un vidrio perfectamente transparente que le separa de los peces que desea atacar, aprende pronto a abstenerse de todo ataque contra la especie que había sido hasta ese momento el objeto de sus frustrados intentos. El elefante y el oso han aprendido a servirse, el primero de su trompa y el segundo de su pata para crear corrientes en un agua sobre la que flota un objeto que codician, a fin de aproximarlo a ellos y así poderlo coger. Los monos aprenden desde la segunda ocasión, a desconfiar de un objeto que les ha causado la primera vez una impresión desagradable. Los animales viejos evitan mejor que los jóvenes las trampas de los cazadores. Las aves en vuelo han aprendido a evitar las líneas telegráficas. En las regiones en que se practica la caza del zorro, los individuos, incluso jóvenes, manifiestan a la salida de la madriguera una prudencia, que no se parece en nada a la de otras regiones. La astucia de ciertas especies persistentes de ratas, es debida manifiestamente al ejercicio habitual de todas sus facultades para escapar del hombre. Los monos han aprendido a romper nueces con piedras, así como a servirse de estas últimas a modo de armas para el combate, ya sea como proyectiles o haciéndolas rodar sobre sus enemigos.

De esta enumeración casi exhaustiva de ejemplos citados por Darwin, se puede ya concluir la probable universalidad del fenómeno del aprendizaje en la rama de los vertebrados. Se impone aquí la cita de un importante fragmento sobre los pájaros cantores, que permite comprender mejor, según Darwin, el alcance evolutivo global del aprendizaje:

«Los sonidos que emiten los pájaros nos ofrecen, desde varios puntos de vista, la mejor analogía con el lenguaje; en efecto, todos los individuos que pertenecen a una misma especie expresan sus emociones por medio de los mismos gritos instintivos, y todos los que pueden cantar ejercen instintivamente esta facultad; pero es el padre, o el padre nutricio, quien le enseña el verdadero canto, e incluso las notas de llamada. Estos cantos y gritos, como demostró Daines Barrington, «no son más innatos en los pájaros que el lenguaje en el hombre. Los primeros ensayos de canto en los pájaros pueden ser comparados a las tentativas imperfectas de los primeros balbuceos del niño». Los jóvenes machos continúan ejercitándose o, como dicen los adiestradores, estudiando durante diez u once meses. En sus primeros intentos, 
apenas se reconocen los rudimentos del futuro canto, pero, a medida que avanzan en edad, se percibe donde quieren llegar, y acaban por cantar muy bien. Las nidadas que han aprendido a cantar de otra especie diferente a la propia, como los canarios que han sido adiestrados en el Tirol, enseñan su nuevo canto a sus propios descendientes. Se pueden comparar, como señala muy juiciosamente Barrington, las ligeras diferencias naturales del canto en una misma especie que habita regiones distintas, «con los dialectos provinciales»; y los cantos de especies relacionadas pero distintas, con las lenguas de las diferentes razas humanas. Nos hemos sentido obligados a exponer los detalles precedentes, para mostrar que una tendencia instintiva a adquirir un arte, no es en absoluto un hecho particular, restringido únicamente al Hombre».

Este pasaje ilustra admirablemente una tendencia de Darwin — su preferencia casi afectiva por las aves - que le conduce a multiplicar las notaciones de carácter antropomórfico, pero intencionalmente, ya que las analogías con características humanas, bajo cierto punto de vista, son según él, más numerosas y más fuertes en este grupo que en ningún otro. Pero este pasaje es igualmente precioso por otras razones: la primera es que existen imitaciones interespecíficas en el Reino animal, y que prueban de forma necesaria que el mecanismo de aprendizaje es el único que determina la forma de una manifestación expresiva como el canto, en ciertas especies de pájaros, de la misma manera que un ejemplo anterior asignaba a este mecanismo, entre perros criados por gatos, el origen de ciertos comportamientos tomados prestados a la especie nutricia. Lo que es innato no es más que una aptitud, una capacidad: la de adquirir comportamientos por imitación y aprendizaje progresivo.

\section{El aprendizaje entre instinto e inteligencia}

Existe, pues, en numerosas especies animales, y como revela la observación, sobre todo en los animales domésticos, una «tendencia instintiva a adquirir un arte». Los aprendizajes efectuados son así la realización de una aptitud y una propensión, instintivas, a dotarse de un comportamiento construido, por la mediación de un proceso de adquisición a menudo imitativo, y por medio de una dinámica reiterativa del ejercicio, es decir, siguiendo un procedimiento susceptible de error y de corrección, que se aleja por consiguiente del instinto para alcanzar la inteligencia. En esta lógica que une, como fases de un mismo continuum de desarrollo, la inteligencia y el instinto, el Hombre aparece, cada vez más, en sus características más racionales, no como un milagro de la creación, sino como la coronación actual de un largo proceso evolutivo, en el curso del cual se eleva en la serie animal, y la inteligencia tiende cada vez más a competir, incluso a suplantar al instinto. En cualquier caso, las cosas no son tan sencillas:

«El pequeño número», escribe Darwin, «y la simplicidad comparativa de los instintos en los animales superiores contrastan notablemente con los de los animales inferiores. Cuvier 
sostenía que el instinto y la inteligencia están en razón inversa; otros han pensado que las facultades intelectuales de los animales criados no son más que instintos gradualmente desarrollados. Pero Pouchet ha demostrado en una interesante memoria ( El instinto en los insectos», Revue des Deux Mondes, febrero 1870, p. 690) que no existe realmente ninguna razón inversa de este género. Los insectos que poseen instintos más notables son ciertamente los más inteligentes. Los miembros menos inteligentes de la clase de los vertebrados, a saber los peces y los anfibios, no tienen instintos complicados; y entre los mamíferos, el animal que más destaca por sus instintos, el castor, posee una gran inteligencia, como admiten todos los que han leído el excelente trabajo del Sr. Morgan sobre este animal (The American Beaver and his works, 1868).

«M. Herbert Spencer (The Principles of Psychology, $2^{\mathrm{a}}$ ed., p. 418-443) sostiene que los primeros destellos de inteligencia se han desarrollado por la multiplicación y coordinación de acciones reflejas; pero aunque la mayoría de los instintos más simples se confunden con acciones reflejas, hasta el punto de que es casi imposible distinguir unos de otras (la succión por ejemplo en animales jóvenes), los instintos más complejos parecen sin embargo haberse formado independientemente de la inteligencia. Estoy no obstante muy lejos de pretender negar que las acciones instintivas puedan perder su carácter fijo y natural, y ser reemplazadas por otras efectuadas por la libre voluntad».

Texto característico del modo habitual de proceder en Darwin, que hace alternar las opiniones más opuestas sobre la cuestión en debate, y parece asumir alternativamente la una y la otra, antes de proponer su propia hipótesis — que a menudo no es percibida por los comentaristas prestos a hacerle tomar netamente partido entre las proposiciones en cuestión. Pero, en este caso, Darwin se ha dotado después de mucho tiempo de los medios para estar de acuerdo con una y con otra de las interpretaciones que opone. Con Cuvier, está de acuerdo en el dominio de la domesticación y en el de la historia del Hombre, pues sabe que los animales domésticos se caracterizan generalmente - al igual que el Hombre a medida que avanza hacia el estado de civilización - por una disminución de la agudeza y actividad de los instintos y por una intensificación de los procesos de aprendizaje. Pero está de acuerdo igualmente con Pouchet sobre la inteligencia de las abejas y las hormigas, y con la ilustración que aporta el castor de Morgan a la tesis eventualmente opuesta de una coextensividad del instinto y de la inteligencia. Reconoce, al mismo tiempo, que Spencer puede tener razón en su interpretación de las primeras manifestaciones de la inteligencia como resultado de una coordinación de actos reflejos, y acepta considerar como indiscernibles los instintos más simples y tales acciones, lo que conduciría, en caso de aceptar completamente esta lógica de desarrollo, a asimilar los instintos desarrollados (o complejos), necesariamente surgidos de instintos más simples, que se confunden así mismo con coordinaciones innatas, a la inteligencia (en tanto que ella misma deriva también de reflejos coordinados). Pero opta, en cuanto a los instintos complejos, por un modo de formación independiente de la inteligencia. Lo que no excluye en absoluto - última conciliación de las opiniones adversas - la probabilidad de un abandono de las acciones instintivas, en provecho de las gobernadas por la voluntad, esto es, 
de un eclipsamiento evolutivo del instinto ante la inteligencia, más frágil y más poderosa a la vez. Sería vano, en este ir y venir sistemático, buscar la posición de Darwin, ya que ésta no se expresa sino algunas líneas más abajo: un acto instintivo es con certeza inferior a una acción inteligente. «Pero la mayor parte de los instintos más complejos», escribe Darwin, «parecen haber sido adquiridos de una forma muy diferente, por la selección natural de las variaciones de actos instintivos más simples. Estas variaciones parecen resultar de las mismas causas desconocidas que, ocasionando ligeras variaciones o variaciones individuales en otras partes del cuerpo, actúan igualmente sobre la organización cerebral, y determinan cambios que, en nuestra ignorancia, consideramos espontáneos». La respuesta de Darwin consiste simplemente en ampliar al instinto la gran ley de la variación y la selección de las variaciones ventajosas. Encontraremos una magnífica aplicación de ésto en la dinámica de la selección y el crecimiento de los instintos sociales, cuyo desarrollo - lejos de contradecir el de la inteligencia - se combina precisamente con el progreso de la razón para favorecer la expansión de los sentimientos altruistas, hasta el punto de rechazar la vertiente eliminatoria de la selección natural y fundar la civilización sobre una base seleccionada de conductas anti-selectivas. Conviene subrayar, a este respecto, el hecho de que los ejemplos tomados por Darwin de Pouchet y Morgan confirman evidentemente que, sea cual sea el phylum considerado, los animales más inteligentes (al igual que los dotados de instintos más complejos) son los que se caracterizan igualmente por la vida «social» más desarrollada. Estos mismos animales de vida social desarrollada son aquellos en los cuales desarrollo del instinto y desarrollo de la inteligencia no son contradictorios.

El aprendizaje entre lo animal y lo humano

Ambivalente por necesidad, la respuesta de Darwin obedece a una doble restricción lógica: en primer lugar, en virtud del continuismo de la teoría del desarrollo gradual, la de no aislar la inteligencia del instinto, si éste se encuentra respecto a aquella en posición de origen, o unido a ella por el hecho de un origen común; por consecuencia, en virtud de la teoría de la selección, asegurar el triunfo de la forma superior de las facultades mentales, lo que no puede concebirse más que por la postulación de variaciones que afectan igualmente a la organización cerebral y están sometidas a la selección, y haciendo entrar el instinto en regresión — según la ley de la extenuación de las formas antiguas - a medida que se afirma el progreso, e incluso, en el Hombre, la victoria evolutiva de la inteligencia. En esta perspectiva, la adquisición de hábitos fijos y automatismos puede aparecer como una regresión en relación al uso libre del razonamiento. La complejificación en red del aparato cerebral parece sin embargo que debe reducir la especialización institiva a sus expresiones más modestas: 
«Aunque un grado elevado de inteligencia», escribe Darwin, «sea ciertamente compatible con la existencia de instintos complejos, como lo prueba el ejemplo del castor y de los insectos de los que acabamos de hablar, y aunque las acciones dependientes de la voluntad puedan en seguida ser llevadas a cabo gracias a la costumbre con la rapidez y la seguridad de una acción refleja, no es sin embargo improbable que exista una cierta oposición entre el desarrollo de la inteligencia y el del instinto, pues este último implica ciertas modificaciones hereditarias del cerebro. Sabemos muy pocas cosas sobre las funciones del cerebro, pero podemos concebir que, a medida que las facultades intelectuales se desarrollan más, las diversas partes del cerebro deben estar en relaciones de comunicaciones más complejas, y que como consecuencia, cada porción diferente debe pues volverse menos apta para responder de una forma definida y hereditaria, es decir instintiva, a las sensaciones particulares. Parece incluso haber ciertas relaciones entre una inteligencia débil y una tendencia fuerte a la formación de hábitos fijos, pero no hereditarios; pues, como me lo ha hecho notar un médico muy sagaz, las personas ligeramente débiles de espíritu tienden a dejarse guiar en todo por la rutina y el hábito, y se les hace tanto más felices cuanto más se les potencia esta disposición».

Tanto más la inteligencia es débil y limitada, más se limita el aprendizaje a gestos invariantes de imitación repetitiva, tan seguros como los actos instintivos, pero incapaces de alzarse al nivel de la invención intelectual o del control inteligente. Existen pues grados entre las instancias y facultades que se movilizan por los procesos de aprendizaje. En el estadio humano, la imitación, tan fundamental en los procesos animales de aprendizaje, se encuentra con relación a la razón —o más ampliamente, la inteligencia - en una posición que recuerda a la del instinto: es primera y sin duda fundamental (en la exposición que hace Darwin del desarrollo de las facultades intelectuales, precede a la atención, la memoria, la imaginación y la razón, en un orden que recuerda parcialmente una psicogénesis de tipo empírico-sensualista); se la encuentra cumpliendo un papel eminente en los animales superiores, alcanzando el nivel de una acción voluntaria en el Mono y el Hombre salvaje. Pero al mismo tiempo y en tanto precisamente que elemental y primitiva, es, como el instinto, el reflejo o el hábito fijo, aquello hacia lo que regresa el individuo que ha perdido o no ha podido alcanzar el uso de las facultades más elevadas que se combinan para producir la novedad intelectual. «La facultad de imitación es potente en el hombre», escribe Darwin, «y sobre todo, como yo mismo he podido comprobar, en el hombre en estado salvaje. La tendencia a la imitación se vuelve excesiva en ciertos estados mórbidos del cerebro; las personas afectadas de hemiplejía o debilidad cerebral repiten inconscientemente durante las primeras fases de la enfermedad, todas las palabras que oyen, ya pertenezcan o no a su propio idioma, o imitan todos los gestos que ven hacer cerca de ellos». El paradigma que asocia en Darwin el Mono, el niño, el salvaje y el idiota para considerar el primitivismo mental a la vez como estadio ancestral del desarrollo de las facultades y como polo de reversión atávico o de regresión patológica, debe sin duda mucho, en su establecimiento - que tuvo consecuencias incalculables en toda la literatura antropológica-, a la Mémoire sur les microcéphales de Carl Vogt (1868), pero también a ciertos trabajos sobre la afasia, fundamentalmente 
los de Bateman. Lo que fue una etapa primitiva, una base, un fundamento, un tronco originario para un desarrollo posterior, se convierte así por el hecho de la evolución, en un estadio relegado o una modalidad de regresión: extenuación de las formas antiguas y reversión atávica son aquí los dos modelos complementarios que permiten pensar la evolución selectiva como modo de eliminación tendencial, pero no inmediata y no total, de lo que ha superado y al mismo tiempo construido.

\section{Aprendizaje e instintos domésticos}

Lo que precede habrá confirmado el alto nivel de coherencia de la teoría de la selección en lo que concierne a la relación de lo orgánico y lo instintivo en la evolución. Esta coherencia toma la forma de un paralelismo lógico que los propios enunciados de Darwin comentan frecuentemente, lo que hace fácil la aprehensión esquemática global de su estructura:

\section{Dominio orgánico}

Variación orgánica fortuita

Heredabilidad de las variaciones orgánicas

Selección de las variaciones orgánicas ventajosas

Refuerzo por el hábito y el uso

Influencia de la domesticación

Regresiones orgánicas por falta de uso

Selección artificial (metódica e inconsciente)

Necesidad de una primera variación natural

Menor estabilidad de las variedades domésticas

Influencia modificadora de los cruzamientos

Posible retorno (reversión ) a caracteres orgánicos

ancestrales

\author{
Dominio instintivo \\ Variación instintiva fortuita \\ Heredabilidad de las variaciones instintivas \\ Selección de las variaciones instintivas ventajosas \\ Idem \\ Idem \\ Regresiones instintivas por falta de uso \\ Idem \\ Idem \\ Menor estabilidad de los instintos domésticos \\ Idem \\ Posible retorno a instintos y comportamientos \\ «salvajes»
}

Esta tabla, que tiene en cuenta todos los datos instintológicos distribuidos en $\mathrm{El}$ origen de las especies y en El origen del Hombre, no tiene otra función que la de subrayar el carácter profundamente unitario de la teoría de la selección, la cual se aplica idénticamente al campo de las variaciones orgánicas y al de las variaciones instintivas. Tanto en un campo como en otro, la ventaja variacional se recibe como adaptativa por el medio, ya sea éste natural o artificial (doméstico). En uno u otro campo, la relación de lo natural y de lo artificial es la misma: la naturaleza suministra la primera variación, material para una selección por el Hombre. Es a partir de un fundamento natural como los «instintos domésticos» (sea el del perro de caza o el del perro pastor) se desarrollan y se transmiten (como los instintos naturales). En los dos 
campos, paralelamente a las adquisiciones dirigidas, la domesticación conlleva disminuciones de aptitudes naturales. La pérdida de ciertos instintos naturales bajo la influencia de condiciones domésticas es correlativa a la adquisición, y eventualmente a la transmisión de nuevos hábitos. Así la tendencia de los perros a atacar a los corderos, los cerdos o las aves de corral, se ha atenuado hasta su casi desaparición, bajo el efecto de la costumbre, de la corrección por el Hombre o de la pura y simple eliminación de los recalcitrantes. Éste es uno de los ejemplos más simples de una interacción (en proporciones relativas no precisables) entre los efectos hereditarios del hábito adquirido (la componente «lamarckiana» de la explicación dada por Darwin de la herencia de los comportamientos) y el mecanismo de la selección artificial o inconsciente. «Podemos concluir a partir de aquí», escribe Darwin, «que bajo la domesticación, se han perdido ciertos instintos naturales, y que otros han sido adquiridos, tanto por el hábito como por la selección y la acumulación, durante generaciones sucesivas, de diversas disposiciones especiales y mentales que han aparecido una vez bajo la influencia de causas que llamamos accidentales a falta de conocerlas. En algunos casos, los hábitos forzados han parecido bastar para provocar modificaciones mentales convertidas en hereditarias; en otros no han provocado ningún resultado, a causa de los efectos de la selección, tanto metódica como inconsciente, pero es probable que en la mayor parte de los casos, las dos cosas han debido actuar simultáneamente.» (El origen de las especies, cap. VII.)

Así, cualquiera que sea la pertinencia del principio lamarckiano —invocado, aquí como en otras partes, a modo de hipótesis autorizada por la siempre subrayada ignorancia de las leyes y los factores de la transmisión hereditaria-, el problema de los instintos domésticos está estrechamente unido en Darwin al del aprendizaje. En el perro doméstico, Darwin evoca una correlación de la domesticación y de la herencia de las modificaciones mentales adquiridas, combinada con la selección efectuada por el criador sobre la base de un instinto natural. Pero en el pájaro cantor o imitador de sonidos humanos, Darwin no evoca más que la singularidad de un aprendizaje reiterado para cada individuo, sobre la base de una capacidad que aún siendo propia de la especie, puede permanecer silenciosa. La cuestión no es condenar ridículamente en Darwin un «error» que sería «lamarckiano» y que, según el caso, sería presentado o no en las hipótesis generales elaboradas por él como tales para avanzar hacia la resolución del gran misterio de la heredabilidad. Habría mucho que decir sobre la ignorancia y la incapacidad teórica de ciertos comentaristas que tachan a Darwin de incoherencia sobre la base de tales aparentes irregularidades. Está claro que la componente lamarckiana en la historia pre-weismanniana de la interpretación de la herencia es casi universal en el discurso de los naturalistas, y que, complementariamente, el lamarckismo es, hablando con propiedad, el inconsciente teórico del criador o adiestrador que buscan «forzar» la naturaleza para modificarla por un condicionamiento externo, y «reforzar» esta naturaleza modificada mediante la reproducción. Darwin elaboró el concepto de selección inconsciente porque sabía que la práctica espontá- 
nea del adiestrador no culto está gobernada por una teoría inconsciente, cuya eficacia no guarda relación con lo que puede ser su grado de exactitud. Además, si se reduce el «lamarckismo» a la acción modificadora directa del medio sobre los seres, el «lamarckismo» es verdad — si consideramos que la «transmisión de hábitos adquiridos» constituye en realidad lo que denominamos cultura- en el universo extra-biológico que se abre, bajo el gobierno del Hombre, hacia el adiestramiento, el aprendizaje y la educación.

Estos elementos serán desarrollados a propósito del Hombre. Pero por el momento, la conclusión principal es que la teoría de que el aprendizaje reposa necesariamente en una «disposición natural a adquirir un arte», es para Darwin el primer elemento de resolución naturalista y continuista del antagonismo metafísico entre naturaleza y cultura al nivel de un ser vivo capaz de integrar comportamientos que obedecen a modelos susceptibles de serle naturalmente extraños. La capacidad de adquirir una educación, ya se trate de adiestramiento, aprendizaje o imitación de modelos, es pues, en su flexibilidad en función de influencias circunstanciales eventualmente condicionantes, la apertura natural a un artificial que se integra naturalmente en la historia evolutiva.

\section{LO NATURAL Y LO SOCIAL: LA TEORÍA DE LOS INSTINTOS SOCIALES Y EL EFECTO RE- VERSIVO DE LA EVOLUCIÓN COMO SUPERACIÓN DEFINITIVA DEL ANTAGONISMO}

\section{Origen de los errores y selección textual}

Durante más de un siglo —el asunto remonta, en Francia, a la traducción problemática y penosamente prologada de El origen de las especies por Clémence Royer (1862) - , se ha querido ver en Darwin al inspirador de las modernas teorías desigualitaristas, al gran prescriptor del eugenismo en sus versiones más duras, al teórico de la eliminación de los débiles, al legitimador naturalista del expansionismo occidental $\mathrm{y}$, especialmente, del imperialismo victoriano, al ideólogo fundador del «racismo científico», al padre efectivo del «darwinismo social» y de la casi totalidad de las sociologías biológicas evolucionistas, y al justificador titulado del egoísmo triunfalista de los poseedores. Se ha visto en él juntos, y sin temor de incompatibilidades ni contradicciones, a Herbert Spencer, Francis Galton, Cecil Rhodes, Arthur de Gobineau y Thomas Robert Malthus. Pero, todas estas alegaciones son no solamente erróneas, sino que se sitúan muy precisamente en el punto opuesto de la verdad historiográfica más verificada, así como de la lógica de la teoría de la descendencia tal y como fue aplicada por el mismo Darwin en el campo de la antropología.

La responsabilidad de esta extraordinaria confusión, que ha velado la exacta interpretación de Darwin durante tanto tiempo, y de la que dan fe tantos comentarios 
de segunda mano y tantos prólogos absurdos a una obra no leída, incumbe en primer lugar a la pantalla tejida alrededor del darwinismo por el evolucionismo filosófico de Spencer, sistema de pensamiento que sirve de marco intelectual al proyecto integrador del ultraliberalismo victoriano, ya instalado en cuanto a sus ejes esenciales cuando la teoría darwiniana emerge en el contexto saturado de luchas ideológicas que es la Inglaterra de los años 1860 .

¿Quién es Spencer? Un ingeniero inglés que repartió su vida entre invenciones técnicas ya realizadas, el periodismo, los ferrocarriles y, a partir de 1840, la constitución de la filosofía y de la sociología política requeridas para la representación ultraliberal del progreso. Apasionado por grandes visiones sintéticas interesadas en reconducir a un principio de inteligibilidad única el conjunto de los datos fenomenológicos accesibles al conocimiento, influenciado inicialmente por la ley del desarrollo diferencial enunciada por von Baer en el campo de la embriología, preocupado después por encontrar en esta «ley» una formulación que alcance un grado de generalidad más elevado, expone su propia «ley de la evolución» en el «Plan general de la filosofía sintética» del 6 de enero de 1858, publicado bajo forma de «Programa» en 1860, dos años antes de los Primeros principios, que aparecen en 1862. La «ley de la evolución» define el paso de los agregados, por un proceso de integración y diferenciación, desde un estado indefinido, incoherente y homogéneo hacia un estado definido, coherente y heterogéneo (proceso que se corresponde con un crecimiento de la complejidad que conduce a los extremos refinamientos de organización de los cuerpos vivos, de la individualidad humana y de las sociedades). La «ley» así enunciada será aplicada a todas las categorías de fenómenos y a todos los dominios del saber, así como a la propia teoría del conocimiento. La vertiente sociológica del pensamiento spenceriano es particularmente representativa de las aspiraciones de la burguesía industrial inglesa: la sociedad es un organismo y evoluciona como un organismo. La adaptación (pensada por Spencer en términos fundamentalmente lamarckianos que no integrarán al darwinismo más que para traicionarlo) es la regla de supervivencia en el seno de una competencia interindividual generalizada: los menos adaptados deben ser eliminados sin consideración ni recursos. Spencer se opondrá así a toda medida tendente a venir en ayuda de los desfavorecidos, y a toda forma de ley de asistencia. Lo que toma prestado de Darwin (aunque, a este nivel, podría ser también de Malthus) es pues el «núcleo duro» de la teoría de la selección tal como la descubre en el mes de octubre de 1858 cuando tiene conocimiento de la intervención común de Darwin y Wallace ante la Linnean Society de Londres. A partir de entonces, su preocupación será aplicarla no tanto en el dominio en que su uso sería legítimo (la evolución de los organismos), sino en un universo en el seno del cual Darwin rehusa su aplicación: la marcha de las sociedades humanas.

Por razones de otro orden, concernientes a la lucha común contra el establishment científico inglés conservador y antitransformista, Darwin acepta una lejana connivencia con Spencer, por quién no sentía simpatía (su Autobiografía de 1876 es a este 
respecto inequívoca) ${ }^{3}$, y una importación terminológica («supervivencia de los más aptos») que quizás tuvieron más efectos negativos a largo plazo que ventajas momentáneas. La confusión entre Darwin y Spencer, entre la teoría de la descendencia modificada por medio de la selección natural y el evolucionismo filosófico-sociológico, tendrá en efecto las peores consecuencias conceptuales, teóricas y políticas en Europa y en el mundo, hasta que la distinción y la oposición reales entre las dos teorías alcance a ser realmente reconocida (ver Tort, 1983) y se llegue a reflexionar sobre ella.

En el medio político-cultural de la clase intelectual victoriana, es evidentemente la confusión la que ha sido seleccionada en detrimento de la distinción, a través de la utilización relativamente indiferenciada de términos con relaciones equívocas para el público, pero con cargas semántica y connotativa profundamente diferenciadas. El deslizamiento que se opera entonces testimonia el poder contaminante de la ideología spenceriana a través de la elección, que se volverá progresivamente dominante entre los mismos biólogos, de un vocabulario de extracción «filosófica»: la evolución spenceriana (noción filosófica) contra la descendencia darwiniana (concepto naturalista), el triunfo o la supervivencia de los más aptos — que se convertirán rápidamente en los más «merecedores» o los más «fuertes»- (noción de uso esencialmente sociológico en Spencer) contra la selección de las variaciones orgánicas e instintivas ventajosas, concepto que, en cuanto a lo instintivo, desembocará en el Darwin de 1871 en posiciones antropológicas (éticas, sociológicas y políticas) diametralmente opuestas a las del portavoz del integrismo liberal.

El primer acto de esta historia es bastante claro: en el texto darwiniano, Spencer, que ha efectuado ya su reducción de Darwin a Malthus (Principios de biología, 1864-1867), se detiene en la expresión «selección natural», de la que hace una crítica ya clásica y ampliamente aceptada por Darwin (la del exceso de «personalización» antropomórfica de una expresión de resonancias voluntaristas, incluso finalistas), la reemplaza por «supervivencia de los más aptos», no la aplica apenas en su dominio

3 «La conversación de Herbert Spencer me parecía muy interesante, pero él no me gustaba particularmente, y no tenía la impresión de que pudiese fácilmente unirme a él. Era, bajo mi punto de vista, extremadamente egoísta. Cada vez que leía uno de sus libros, desbordaba de admiración por su talento fulgurante, y a menudo me he preguntado si, en el futuro, no sería alzado al mismo rango que grandes hombres como Descartes, Leibniz, etc. (sobre los cuales, a decir verdad, sé muy pocas cosas). Sin embargo, los escritos de Spencer no me han servido de nada en mi propio trabajo. Su manera deductiva de tratar el tema es totalmente opuesta a mi forma de espíritu. Sus conclusiones no me han convencido jamás; y cada vez que leía una de sus discusiones, me decía: «He aquí algo que sería un muy buen tema para una media docena de años de trabajo». Sus generalizaciones fundamentales (¡de las que algunos han comparado la importancia a la de las leyes de Newton!), son quizás, osaría decir, muy válidas desde un punto de vista filosófico, pero de una esencia tal que me parecen no tener ningún uso estrictamente científico. Perteneciendo por esencia a las definiciones más que a las leyes de la naturaleza, no permiten predecir lo que se producirá en un caso particular. De todas maneras, no han sido para mí de ninguna utilidad». (Autobiografía de 1876, texto restablecido en su integridad por Nora Barlow en 1954 ). 
legítimo (la esfera de lo vivo, en donde permanece estrechamente partidario de la «acción directa» y de los «factores primarios» lamarckianos), pero se sirve de ella como de la clave de una antropología social evolucionista y de una sociología en donde su utilización contradice la, finamente dialéctica, hecha por Darwin.

Es importante, pues, identificar, en la lógica de la antropología de Darwin tal como se expone soberbiamente en El origen del Hombre y la selección sexual (1871), lo que la opone al hiperseleccionismo biológico-social de Spencer, verdadero inventor del impropiamente denominado «darwinismo social», y creador de todos los paradigmas comunes a las «sociobiologías» ulteriores de la historia.

El efecto reversivo de la evolución (o porqué Darwin no era «darwinista social»)

Una vez más, recurriremos aquí, para evitar paráfrasis artificiales, al desarrollo que el Dictionnaire du darwinisme consagra al concepto de efecto reversivo de la evolución.

Concepto clave de la antropología darwiniana (a distinguir de la antropología evolucionista), el efecto reversivo de la evolución (como fue designado por nosotros en 1983) es el que permite pensar, en Darwin, el pasaje entre lo que será denominado por comodidad y aproximación la esfera de la naturaleza, regida por la estricta ley de la selección, y el estado de una sociedad civilizada, en el interior de la cual se generalizan e institucionalizan conductas que se oponen al libre juego de esta ley. $\mathrm{Si}$ este concepto no está denominado en ninguna parte de la obra de Darwin, está sin embargo descrito y opera en ciertos desarrollos importantes (fundamentalmente los capítulos IV, V y XXI) de El origen del Hombre de 1871, que es preciso considerar como su tercera gran obra de síntesis, y como la consecución coherente, en el campo de la historia evolutiva del Hombre natural y social, de la teoría de la selección desarrollada en el Origen de las especies de 1859. Es el resultado de una paradoja identificada por Darwin en el curso de su ensayo de extensión al Hombre de la teoría de la descendencia, y de su esfuerzo para pensar el devenir social y moral de la humanidad como una consecuencia y un desarrollo particular de la aplicación anterior y universal de la ley de la selección en la esfera de lo vivo.

Esta paradoja se puede formular así: la selección natural, principio director de la evolución que implica la eliminación de los menos aptos en la lucha por la vida, selecciona en la humanidad una forma de vida social cuya marcha hacia la civilización tiende a excluir cada vez más, a través del juego ligado de la ética y de las instituciones, los comportamientos eliminatorios. En términos simplificados, la selección natural selecciona la civilización, que se opone a la selección natural. ¿Cómo resolver esta aparente paradoja? 
La resolveremos desarrollando simplemente la propia lógica de la teoría de la selección. La selección natural —se trata en Darwin de un punto fundamentalselecciona no solamente variaciones orgánicas que presentan una ventaja adaptativa, sino también instintos. Entre estos instintos ventajosos, los que Darwin denomina los instintos sociales, han sido particularmente retenidos y desarrollados en el Hombre, como lo demuestran el triunfo universal del modo de vida social en el seno de la humanidad, y la tendencia hegemónica de los pueblos «civilizados». Ahora bien, en el estado de «civilización», resultado complejo de un incremento de la racionalidad, de la influencia creciente del sentimiento de «simpatía» y de las diferentes formas morales e institucionales del altruismo, se asiste a una inversión cada vez más acentuada de las conductas individuales y sociales en relación a lo que sería la continuación pura y simple del funcionamiento selectivo anterior: en lugar de la eliminación de los menos aptos, aparece, con la civilización, el deber de asistencia que pone en marcha, al contrario, múltiples actuaciones de socorro y rehabilitación; en lugar de la extinción natural de los enfermos y débiles, su salvaguardia por la movilización de tecnologías y saberes (higiene, medicina, deporte) de cara a la reducción y compensación de las deficiencias orgánicas; en lugar de la aceptación de las consecuencias destructoras de las jerarquías naturales de la fuerza, del número y de la aptitud vital, un intervencionismo reequilibrador que se opone a la descalificación social. Por la vía de los instintos sociales, la selección natural, sin «salto» ni ruptura, ha seleccionado así su contrario, o sea: un conjunto normado, y en extensión, de comportamientos sociales anti-eliminatorios -ésto es, anti-selectivos en el sentido que reviste el término de selección en la teoría desarrollada por El origen de las especies-, así como, correlativamente, una ética anti-seleccionista (anti-eliminatoria) traducida en principios, reglas de conducta y leyes. La emergencia progresiva de la moral aparece pues como un fenómeno indisociable de la evolución, y he aquí una consecuencia normal del materialismo de Darwin, y de la inevitable extensión de la teoría de la selección natural a la explicación del devenir de las sociedades humanas. Pero esta extensión, que demasiados teóricos, engañados por el telón que había tejido alrededor de Darwin la filosofía evolucionista de Spencer, interpretaron prematuramente sobre el modelo simplista y falso del «darwinismo social» liberal (aplicación a las sociedades humanas del principio de la eliminación de los menos aptos en el seno de una competencia vital generalizada), no puede efectuarse en todo rigor más que bajo la modalidad del efecto reversivo, que obliga a concebir la propia inversión de la operación selectiva como base y condición del acceso a la «civilización». Ésto es lo que prohibe definitivamente que la sociobiología, que defiende por el contrario, en oposición a toda la lógica antropológica de Darwin, la idea de una continuidad simple (sin inversión) entre naturaleza y sociedad, pueda reclamarse, con derecho, del darwinismo. La operación reversiva es la que fundamenta la legitimidad final de la oposición naturaleza-cultura, evitando la trampa de una «ruptura» mágicamente instalada entre sus dos términos: la continuidad evolutiva, a través de esta operación de inver- 
sión progresiva unida al desarrollo (él mismo seleccionado) de los instintos sociales, produce de esta manera no una ruptura efectiva, sino un efecto de ruptura que proviene de que la selección natural se ha encontrado en el curso de su propia evolución, sometida ella misma a su propia ley - la forma nuevamente seleccionada, que favorece la protección de los «débiles», imponiéndose, por ventajosa, sobre la forma antigua que privilegiaba su eliminación. La nueva ventaja no es ya de orden biológico: se ha convertido en social.

Hemos simbolizado esta inversión progresiva a través de la imagen topológica de la torsión del anillo de Möbius (Tort, 1992), señalando sin embargo que el verdadero modelo darwiniano del fenómeno era el de la divergencia evolutiva seleccionada en el interior mismo del devenir de la ley selectiva.

Darwin permite así, como a menudo hemos explicado, pensar la relación naturaleza / civilización escapando al doble dogmatismo de la continuidad (discurso de tipo «sociobiológico») y de la ruptura (discurso de tipo «levi-straussiano»), que evita tanto la recíproca exterioridad de lo biológico y lo social (un sociologismo que excluiría metodológicamente la toma en cuenta de cualquier factor naturalista) como el reduccionismo ordinario, para el cual todo lo social no es más que la traducción de impulsos surgidos de un nivel cualquiera de la biología (variable según el estado histórico de las investigaciones sobre lo viviente ). En pocas palabras, Darwin hace posible, en la lógica de esa relación compleja, un continuismo materialista que impone la representación de una inversión progresiva (pensable en términos de divergencia seleccionada en el interior de la selección natural, ella misma en evolución, y sometiéndose de hecho a su propia ley antes de entrar en regresión) que se separa de artefactos teóricos tales como el «salto cualitativo», salvando sin embargo evolutivamente la independencia final de las ciencias del Hombre y de la sociedad. Correlativamente, Darwin produce, mediante el concepto dialéctico de la selección de las conductas anti-selectivas y del sentimiento de simpatía, acoplado al de crecimiento de la racionalidad y al tema de la importancia creciente acordada por cada sujeto a la «opinión pública», una teoría materialista de las bases de la moral que preserva al mismo tiempo la independencia conquistada por las decisiones y la reflexión éticas (gracias al efecto de ruptura producido por la inversión), permitiendo sin embargo sustraer éstas a la influencia dogmática de las morales de la obligación trascendente (ver Tort, 1995).

Las razones de una larga confusión

Lo que precede inmediatamente pone en relieve el esquema dialéctico de la «transición» entre lo biológico y lo cultural en Darwin (para seguir oposiciones consagradas que adquieren aquí un sentido auténticamente evolutivo). El hecho es que con 
Darwin, teniendo en cuenta la formidable transformación del universo mental que implica, una vez comprendido, su continuismo evolutivo, la distinción teorizable entre los dos tipos de realidades (biológicas y culturales) se desvanece en tanto que esencialista, para reformularse como dialéctica: he aquí el efecto de una teoría materialista consecuente, y no hay que sorprenderse por ello. Pero el vocabulario y los esquemas didácticos e ideológicos no se pliegan fácilmente a la dialéctica y prefieren las oposiciones tajantes, sea porque son más fáciles, sea porque son operativas con respecto a apuestas de cara a las cuales la exactitud parece menos importante que la claridad. Esto es exactamente lo que ha sucedido con la interpretación de la antropología de Darwin. Se la ha clasificado sin conocerla, en nombre de la información que se creía tener sobre el «núcleo» de la teoría (continuismo bioselectivo simple y homogéneo) en la categoría de las sociologías biológicas, es decir, aún, del lado de Spencer (pero también de Espinas, incluso de Vacher de Lapouge, etc.). Allí se esboza la respuesta a la cuestión que plantean todavía, muy ingenuamente, los que experimentan una última resistencia a admitir la operación en Darwin de lo que acabamos de describir bajo el concepto de efecto reversivo de la evolución: ¿por qué si verdaderamente estaba en El origen del Hombre, el efecto reversivo no se vio?

La respuesta se enunciará en tres puntos.

El primero, lo hemos dicho ya, atañe a la historia del recubrimiento inicial de la lógica darwiniana por una «epistemología» dominante que se encarna en el sistema de Spencer. El spencerismo tiende un telón. Impone la forma filosófica de la nueva organización económica y social bajo el motivo general de una ley de evolución que no es más que una sofisticación, con refuerzos científicos, de la teoría del progreso desarrollada en el siglo precedente por los primeros teóricos del liberalismo. (Sobre las complejas relaciones entre Spencer, el positivismo comtiano y los primeros pensadores liberales del «progreso», ver Tort, 1983; Spencer, 1987; y Tort, 1989).

El segundo concierne al compromiso darwino-spenceriano evocado más arriba.

El tercero concierne por último a la historiografía circum-darwiniana. Con una insistencia y un poder de convicción proporcionales al compromiso dentro de sus filas, este último condicionado por una convergencia de intereses a veces bastante dispares, los partidarios de Darwin, fortalecidos por el éxito real, pero aún poco afirmado de El origen de las especies, incitaron a su autor a salir de su reserva en cuanto al Hombre, y a incluir a este último en el cuadro de la teoría de la descendencia. Ésto es: a extender al Hombre que vive en sociedad y a toda forma de civilización la teoría de la descendencia modificada por medio de la selección natural. Se esperaba pues simplemente que Darwin, derribando el último tabú, franquease la frontera metafísica que separaba aún al Hombre del resto del universo vivo, designándole expresamente como un miembro evolucionado del Reino animal y que comparte con el conjunto de este último, y especialmente con sus representantes evolutivamente más próximos, una suma importante de características comunes, orgánicas y, eventualmente, psíquicas y comportamentales. Los amigos de Darwin esperaban así, y con ellos todo el 
público alrededor del cual había sido cultivada esta espera, la continuación de $E l$ origen de las especies. De esta manera, El origen del Hombre es acogido desde su aparición como la continuación homogénea, y como el esperado complemento para la constitución de una doctrina naturalista global y coherente que descanse en la aplicación de la teoría de la selección al conjunto de las criaturas, una vez realizada la necesaria transgresión de los obstáculos teológicos. Ésto explica suficientemente que aún sin haberla leído, cada uno pensara saber lo que allí había escrito, o que leyéndola, los comentaristas no estuvieran atentos más que a los motivos que explicitaban los lazos con la animalidad, sin percibir la suerte particular — la regresión - que allí sufría la selección natural en su versión estrictamente biológica. «La selección natural», escribe Darwin, «parece no ejercer más que una influencia muy secundaria sobre las naciones civilizadas, en tanto que no se trata más que de la producción de un nivel de moralidad más elevado y de un número más considerable de hombres bien dotados; le debemos sin embargo la adquisición original de los instintos sociales» ( $E l$ origen del Hombre, cap. V). Y aún más: «Por más importante que haya sido y aún sea la lucha por la existencia, otras influencias más importantes han intervenido en lo que concierne a la parte más elevada de la naturaleza humana. Las cualidades morales progresan en efecto directa o indirectamente, más bien por efecto del hábito, el razonamiento, la instrucción, la religión, etc., que por la acción de la selección natural, aunque puedan con certeza atribuirse a la acción de esta última, los instintos sociales, que son la base del desarrollo del sentido moral». (Ibid., cap. XXI.)

La antropología darwiniana era pues interpretada antes de ser conocida. El «progresismo» naturalista — cuyo mayor interés radicaba en ser portador de un último golpe al dogma creacionista estableciendo una teoría de la descendencia unitaria y completa - no podía adivinar que triunfando en este terreno, iba a unirse a la vía de una deriva bio-sociológica en la cual el darwinismo real iba a perderse. Y es rigurosamente cierto que el efecto principal de la batalla en favor de las ideas de Darwin hasta el umbral del siglo XX no tuvo por efecto principal más que imponer tendencialmente el transformismo, sin hacer por tanto justicia a la originalidad de las ideas ni del método darwinianos. Los «darwinista sociales» spencerianos o haeckelianos vencían en un terreno -El Hombre - en donde Darwin aún dudaba en considerarse un verdadero experto, a pesar de su magnífica obra de 1871, mientras que Spencer preparaba su enorme Sociología descriptiva (1873) y Haeckel meditaba su Antropogenia (1874). El propio Marx, apremiado por extraer su conclusion de la lectura de El Origen de las especies, y pasado el momento de su primer entusiasmo materialista de 1860, responderá más a los «darwinistas» que al mismo Darwin cuando incriminará en este último la proyección sobre la naturaleza de los esquemas funcionales y dinámicos de la sociedad competitivista liberal (Carta a Engels de 1862). Engels tendrá menos excusas en 1873 en el Anti- Dühring cuando hablará de «torpeza malthusiana» a propósito de Darwin, y cuando repetirá esta desgraciada crítica en 1875 en la Dialéctica de la Naturaleza, cuatro años posterior a El origen del Hombre. Así, 
hoy como ayer, y por el juego de presiones históricas fácilmente identificables, una izquierda de inspiración marxista, a pesar de su interés por una teoría materialista fundamental del devenir, y de las analogías que pueda encontrar entre la lucha histórica de clases y la lucha natural por la existencia, ataca aún, de vez en cuando, a Darwin, al igual que, del otro lado, la derecha ultra-liberal (social-darwinista o eugenista) le elogia, cometiendo el mismo error, el de confundir la antropología de Darwin con el «darwinismo social» de sus epígonos.

La segunda causa de error y confusión fue el nacimiento del eugenismo. Su primer y principal teórico fue un primo de Darwin, Francis Galton, estadístico apasionado en particular por el estudio de los fenómenos hereditarios. Hizo algunos estudios médicos, fue marcado profundamente por la lectura en 1859 de El Origen de las especies, y desde 1865 comenzó a producir las tesis fundamentales de lo que con él iba a tomar, sobre un fondo de hereditarismo y selección artificial aplicada a la humanidad, el nombre de eugenismo. Su proposición de base es bastante simple: puesto que la selección natural asegura en el conjunto del mundo viviente la diversidad de las especies y la promoción de los más aptos a partir de la elección de las variaciones biológicas ventajosas, el mismo efecto debería producirse en la sociedad humana con respecto a los caracteres intelectuales. Ahora bien, la civilización desarrollada traba el libre juego de la selección natural, permitiendo la protección y la reproducción de las existencias mediocres. Es pues necesario comprometer una acción de selección artificial institucionalizada a fin de compensar este déficit y aligerar esta carga. A la luz de El origen del Hombre de 1871, se entiende que esta actitud era inconciliable con lo que iba a ser la antropología de Darwin, y contradictoria con el darwinismo estrictamente entendido (repetimos, el de Darwin), para el que la selección artificial no puede aplicarse más que a las plantas cultivadas y a los animales domésticos. Para Darwin, en efecto, aquel que tratase a otro ser humano, sea cual sea su grado de alejamiento racio-cultural o su fragilidad física o psíquica, como algo diferente que su «igual» contravendría a la ley civilizacional de la extensión progresiva de la simpatía y regresaría en la escala de la evolución humana hasta el estado de salvajismo ancestral. Galton, que no será más consciente que otros de lo que Darwin escribirá en 1871 y no pudiendo serlo en todo caso en los años de 1860, continúa pues su tarea de explicación militante de la urgencia de una política eugenista científica para frenar la probable degeneración del grupo social, intentando demostrar el carácter hereditario de las cualidades intelectuales, y establecer estadísticamente la estricta herencia del genio (Hereditary Genius, 1869), haciendo total abstracción de los factores educativos. El eugenismo de Galton, como lo señala el propio Darwin (El origen del Hombre, cap. V), era hostil a la «reproducción de los pobres y los imprevisores», considerada como un obstáculo al aumento numérico de los hombres «superiores». Darwin concluirá en cuanto a sí, a la inversa, defendiendo el principio opuesto de una igualdad de oportunidades en la concurrencia social.

Afinando la aplicación de los métodos estadísticos a la biología, los continuadores de Galton - los «biometras» ligados al principio de la selección darwiniana, espe- 
cialmente Karl Pearson- compartieron con él la responsabilidad histórica de la primera elaboración de la doctrina eugenista. Se podría hacer notar aquí que la inflexión propia del trabajo de Galton, al sustituir la importancia dada por Darwin a la individualidad biológica y sus avatares evolutivos por la de un conjunto poblacional sometido en tanto que tal a la selección, favorece de entrada a todo discurso y empresas futuros que recomendarán como necesario, en nombre de la mejora de la calidad biológica del grupo, la eliminación de ciertas categorías de individuos portadores de «malas» variaciones. La oposición entre las concepciones galtoniana y darwiniana estalla, por otra parte, a finales de 1870, en el seno de una historia compleja que es a la vez la de la emergencia de la biología matemática y la de las ideologías de la optimización normalizante del nivel biológico de las poblaciones. Sólo vamos a retener aquí la idea de encierro en sí misma de la racionalidad matemática, de olvido de las realidades biológicas del organismo y de desaparición del individuo detrás de un telón de medidas, caracteres cuantificables y abstracciones estadísticas. Como hace a otro nivel la antropología física, la biometría, que conlleva el rasgo constitutivo de una «deshumanización» metodológica de su objeto de estudio, era perfectamente susceptible, bajo la acción de ciertas fuerzas político-ideológicas, de servir de instrumento a prescripciones y prácticas intervencionistas en la vida y la reproducción de los individuos, en nombre de la calidad biológica de la comunidad, y tanto más cuando en su principal inspirador, Galton, la inclinación elitista era inicial, y que su primer continuador, Pearson, optaba claramente por una «modificación de la fertilidad relativa de las buenas y de las malas estirpes» del grupo social (fórmula que, de paso, vuelve problemática y siempre inestable la distinción entre un eugenismo «positivo» y un eugenismo «negativo»). Correlativamente, la ciencia cuantitativa naciente alimentaba ya el proyecto de una anexión de las ciencias sociales. La genética mendeliana, tras un tormentoso debate con la biometría, lo integrará progresivamente en su vertiente cuantitativa, y los genetistas tomarán entonces el relevo del eugenismo, sostenido igualmente por numerosos médicos, naturalistas y sociólogos biologistas en el curso de los primeros decenios del siglo XX.

La cuestión de las relaciones entre darwinismo social, eugenismo y racismo está desarrollada en el Dictionnaire du darwinisme con una agudeza quizás sin precedentes. Existen distinciones históricas y teóricas entre estas tres corrientes, al tiempo que solapamientos parciales. Una cosa está fuera de duda: el eugenismo, en su moderno acto fundacional (galtoniano), está íntimamente penetrado de la idea, que será retomada de manera universal, según la que en las sociedades civilizadas, la selección natural, por el hecho de las diversas medidas de protección social y sanitaria, así como las condiciones generales de confort que mantienen a las existencias individuales al abrigo de todo riesgo importante, no juega ya el papel discriminante y eliminador que aseguraba en la «naturaleza», y cuyo efecto era privilegiar a las mejores estirpes en el plano de la supervivencia diferencial y la reproducción. De donde el temor, apoyado con mil ejemplos, de una «degeneración» global (tema ya aclimatado 
por la psiquiatría hereditarista) de las poblaciones humanas al nivel de sus características biológicas. De donde en fin la recomendación de medidas institucionales de intervención correctora y compensatoria tendentes a restaurar la calidad biológica del grupo por la introducción de una selección artificial aplicada a sus miembros. Ahí se encuentra el núcleo teórico del eugenismo moderno, y ya hemos visto hasta que punto Darwin se oponía a ello.

La extraordinaria complejidad de las relaciones entre eugenismo y darwinismo social en los diferentes paises que fueron el teatro de la difusión de las ideas nacidas de la biología moderna, es tal que ninguna regla absolutamente constante podría ser formulada en cuanto a una homogeneidad doctrinal realmente estable, a excepción quizás del esquema de base que acaba de ser descrito (falta de selección natural $\longrightarrow$ degeneración $\longrightarrow$ selección artificial). En USA, que es a la vez el territorio de la exportación masiva del «darwinismo social» ultraliberal de Spencer (que no implicaba, al menos en su fundador, la prescripción de medidas eugenistas o racistas) y una tierra de inmigración multirracial, de esclavitud y de segregación, el eugenismo esterilizador de los Davenport y los Laughlin incidió cruelmente durante un largo período que comenzó hacia 1904. Los «débiles de espíritu», los portadores de enfermedades «hereditarias» y los pobres son los blancos de este terrrible movimiento. Análogas prácticas se desarrollan en los paises escandinavos. En Alemania, la gran figura de Ernst Haeckel, naturalista lamarckiano fundador del «Social-Darwinismo» nacional, se mezcla al eugenismo y al Kulturkampf bismarckiano, desarrollando en sus obras de vulgarización los temas de la eutanasia y de la «selección espartana», que se reencontrarán en el corazón de los temas claves del nazismo, preparado ideológicamente por los «higienistas raciales» Ploetz, Rüdin, Eugen Fischer y muchos otros. Las medidas nazis de esterilización humana se desplegarán entre 1933 y 1940, y el programa de eliminación de los judíos, considerados como disgénicos, será aplicado a continuación.

En Francia, el eugenismo de un Vacher de Lapouge permanece estrechamente unido a los eslogans de un «darwinismo social» poco matizado, y las declaraciones eugenistas permanecerán esencialmente no aplicativas, aunque la proximidad de Alemania y de la depuración nazi hagan soñar más tarde a algunos médicos tales como el gobiniano René Martial. El eugenista más conocido en Francia fue quizás el médico (emigrado a USA) Alexis Carrel, autor de la célebre obra L'Homme, cet inconnu (1935), mediocre repetidor del discurso ordinario de la higiene racial alemana y del eugenismo esterilizador americano, partidario declarado en 1936 de las medidas nazis de depuración biológica de la raza, y promotor de la utilización de las cámaras de gas para el tratamiento «humano y económico» del problema planteado a la sociedad por ciertos delincuentes y enfermos mentales. Carrel, que crea y dirige bajo la autoridad del Mariscal Pétain una «Fundación francesa para el estudio de los problemas humanos» con vocación eugenista, muy próxima de la que el noruego Mjöen proyectó en 1915, y que envia a sus equipos a encuestar sobre la «calidad biológica» de las familias inmigrantes durante la Ocupación. Carrel, que sueña con una «aristocracia biológica heredi- 
taria» y con el fin de la democracia. Carrel, de cuyo nombre Francia desembaraza hoy sus calles y universidades, en un movimiento de toma de conciencia que estamos contentos de haber contribuido a suscitar (ver Bonnafé y Tort, 1992). Carrel, que no cuenta ya hoy con más admiradores y furiosos defensores que algunos médicos de extrema derecha, un insípido historiador del CNRS, e ideólogos del Frente Nacional.

De Darwin al nazismo, la vía es sinuosa y atravesada de corrientes cuya característica común es la traición del pensamiento integralmente desarrollado de Darwin. La verdad sobre lo que Darwin ha escrito sobre el Hombre debe ser buscada no en la obra en la cual no lo menciona (El Origen de las especies), sino en aquella en la que habla de él (El origen del Hombre). El transformismo darwiniano en antropología era un humanismo materialista abierto sobre una ética asimilativa y opuesta a toda forma de opresión y coerción desigualitaristas. Uno de los méritos del Dictionnaire es sin duda el de permitir a los lectores el acceso a los textos que definitivamente efectúan esa demostración.

\section{CONCLUSIÓN}

Será preciso repetir aún muchas veces, a falta de conseguir que se lea El origen del Hombre con la inteligencia requerida por su articulación en el seno de la coherencia dialéctica de la teoría selectiva, que Darwin no era ni eugenista, ni racista, ni neo-malthusiano, ni imperialista, ni proesclavista, sino muy exactamente el enemigo de todos estos dispositivos de fuerzas ideológicas que han intentado recurrentemente utilizar su prestigio científico para dotarse del anclaje naturalista que necesitaban tras cada una de sus resurgencias. Darwin tomó claramente posición contra la eugenesia propuesta por Galton ${ }^{4}$; se comprometió personalmente contra el racismo oponiéndose, en tanto que miembro de la Ethnological Society, al racismo reivindicado por James Hunt y la Anthropological Society, y argumentando esta posición ética en El origen del Hombres; por otra parte, habiendo tomado de Malthus un elemento de modelización matemática que aplicó a las dinámicas de crecimiento de las poblaciones vegetales y animales sobre territorios limitados en cuanto a sus recursos, rehusó la aplicación de las recomendaciones malthusianas a las sociedades humanas ${ }^{6}$; combatió igualmente los efectos de extenuación física y moral de las poblaciones indígenas introducidos en ultramar por la violencia mortífera de la dominación colonial; odiaba la esclavitud y cualquier forma de humillación brutal del hombre por el hombre, como puede comprobarse leyendo el Viaje de un naturalista, las cartas a Asa

\footnotetext{
4 Ver Anexo 1.

5 Ver Anexo 2.

6 Ver Anexo 3.
} 
Gray sobre la esclavitud de los Negros en los Estados del Sur de USA después de la Guerra de Secesión 7 , y, una vez más, El origen del Hombre.

El mantenimiento pertinaz, contra la evidencia lógica, histórica y textual, de los errores que consisten en convertir a Darwin en responsable de todas las plagas desigualitaristas y supremacistas, no puede ser totalmente inocente en quienes detentan desde siempre la posibilidad de acceder a las fuentes. Contra estos «errores», entre otros, se alza hoy el Dictionnaire du darwinisme et de l'évolution.

La ya vieja obligación de oponernos a lo que, en la sociobiología contemporánea, ha retomado a su cargo la errónea pretensión del antiguo «darwinismo social» - la de encarnar el darwinismo integral en lo que algunos querían ver sus consecuencias más extremas-, no fue una pérdida de tiempo ${ }^{8}$. Además de que nos permitió analizar un ejemplo característico de ideología para-científica con fuerte grado de recurrencia, nos permite hoy, por la explicitación de la lógica restaurada de la teoría darwiniana, mostrar cómo - a la inversa de las interpretaciones no competentes que fueron largo tiempo dominantes por el hecho de adecuarse a intereses ideológicos muy determinados-, Darwin hace posible un materialismo extendido a la ética y a la comprensión científica de los datos y los actos de la conciencia humana. En el movimiento dialéctico de autosuperación de la dinámica selectiva, que desembaraza de toda causalidad trascendente la emergencia de la civilización como reino de los valores ético-sociales, Darwin efectúa el descubrimiento genealógico sin el cual el racionalismo laico no puede valer como base gnoseológica para una comprensión coherente de lo que otros han llamado el fenómeno humano. En el mismo gesto que autoriza esta inteligencia y la libera, Darwin, que acaba su recorrido naturalista por la indicación sin equívoco de lo que constituye la especificidad de la civilización (el paso al reverso de la selección), funda la existencia legítima de las ciencias del hombre y de la sociedad como ciencias pertinentes de un objeto complejo, el cual, por ser precisamente el punto de emergencia de vías evolutivas inéditas, ha convertido en específico el aparato destinado a su conocimiento.

\footnotetext{
7 Ver Anexo 4.

8 Ver TORT, P. (dir.), Misère de la sociobiologie, París, PUF, 1985.
} 


\section{ANEXOS}

\section{DARWIN ANTI-EUGENISTA}

Con ocasión de un artículo sobre el «eugenismo francés» publicado en el número de junio de 1995 de La Recherche, el Señor Alain Drouard (quien ha consagrado gran actividad a intentar establecer que el médico vichista Alexis Carrel, partidario declarado en 1935 de la utilización de gases letales contra diversas categorías de delincuentes y enfermos mentales, miembro del Parti Populaire Français pro-nazi durante la ocupación alemana, admirador de Mussolini y aprobador de las primeras medidas nazis de depuración biológica de la raza, era un humanista víctima de un «efecto de posición y sobredeterminación histórica» promotor de una eugenesia solamente «positiva») declara, con ayuda de citas incompletas, a Darwin eugenista. Aunque hoy en día parezca superfluo a los especialistas responder una vez más a este contrasentido, se invitará a su autor a leer el párrafo siguiente de El origen del Hombre, en el que Darwin habla en su propio nombre (la tergiversación más frecuente consiste, por el contrario, en aislar párrafos en los cuales el naturalista inglés se refiere y examina las tesis de algunos de sus contemporáneos como si fuesen asumidas por él):

«Nuestro instinto de simpatía nos impulsa a socorrer a los desgraciados; la compasión es uno de estos productos accidentales de este instinto que hemos adquirido originalmente, al mismo título que los otros instintos sociales de los que forma parte. La simpatía, por otra parte, por las causas que ya hemos indicado, tiende siempre a convertirse en más amplia y más universal. No podríamos restringir nuestra simpatía, admitiendo incluso que la inflexible razón hiciese de ello una ley, sin atentar a la parte más noble de nuestra naturaleza. El cirujano debe hacerse inaccesible a todo sentimiento de piedad en el momento en el que practica una operación, porque actúa por el bien de su paciente; pero si, con propósito deliberado, olvidara a los débiles y a los enfermos, no podría tener en perspectiva más que una ventaja eventual, al precio de un mal presente considerable y cierto. Debemos pues sufrir sin lamentarnos, de los efectos indudablemente perniciosos que resultan de la persistencia y de la propagación de los seres débiles.» (El origen del Hombre, cap. V.)

\section{DARWIN ANTIRACISTA}

«A medida que el hombre avanza en civilización y que las pequeñas tribus se reúnen en comunidades más numerosas, la simple razón indica a cada individuo que debe extender sus instintos sociales y su simpatía a todos los miembros de la misma nación, aunque no le sean personalmente conocidos. Alcanzado este punto, sólo una barrera artificial puede impedir a sus simpatías extenderse a todos los hombres de todas las naciones y todas las razas. La experiencia demuestra, desgraciadamente, cuanto tiempo es preciso antes de que consideremos como nuestros semejantes a los hombres que difieren considerablemente de nosotros por su aspecto exterior y sus costumbres.» (El origen del Hombre, cap. IV) 


\section{DARWIN ANTI-MALTHUSIANO}

Al final de El origen del Hombre (cap. XXI, «Conclusión principal»), Darwin, que defiende sus propias conclusiones contra todas las formas de selección artificial aplicada a las sociedades humanas, escribe:

«No es necesario pues emplear medio alguno para disminuir mucho la proporción natural en la que aumenta la especie humana, aunque este aumento entrañe numerosos sufrimientos».

Se trata de no poner trabas mediante ningún artificio coercitivo o limitativo al libre juego de una competición en la que los individuos, cualquiera que sea su origen social, deben tener oportunidades iguales de probar su valor. Darwin defiende en todos sus términos el derecho de los más pobres a la procreación, pues «debería en ello haber concurrencia abierta para todos». El malthusianismo es rechazado de entrada porque contradice el principio mismo de la continuación de la selección natural en el seno de las sociedades humanas. Pero es preciso no olvidar que las modalidades de esta «continuación» son éticas, esto es opuestas a la versión eliminatoria, suplantada en la evolución, de la selección natural. El intervencionismo social de Darwin es pues reequilibrador: se trata de restablecer las condiciones de una igualdad de oportunidades de cara a la obligación civilizacional de producir «un gran número de hombres bien dotados», es decir haciendo el mayor caso del altruismo y la solidaridad.

\section{DARWIN ANTI-ESCLAVISTA}

«No querría pertenecer a los Tories, aunque no fuera más que por su sequedad de corazón con respecto a la esclavitud, lo que debería ser un escándalo para las naciones cristianas». (Carta a J.S. Henslow del 18 de mayo de 1832.)

«Me regocija el corazón conocer como marchan los acontecimientos en Inglaterra. ¡Hurra por los honestos Whigs! Espero que ataquen pronto a esta lacra monstruosa de nuestra tan alabada libertad: la esclavitud colonial. He visto suficiente de la esclavitud y de las disposiciones de los negros para estar disgustado por las mentiras y las estupideces que se oyen a este respecto en Inglaterra». (Carta a J.M. Herbert del 2 de junio de 1833).

«Algunos, entre los cuales me encuentro, desearían incluso que el Norte emprendiera una cruzada contra la esclavitud, aunque el sacrificio costase la vida a millones de hombres. A fin de cuentas, la causa de la humanidad sería una amplia compensación por un millón de horribles muertes. ¡Tiempos extraordinarios los que vivimos! ¡Dios mío! ¡Como me gustaría ver abolida esta maldición, grande entre todas: la esclavitud !» (Carta a Asa Gray del 5 de junio de 1861).

\section{BIBLIOGRAFÍA}

Bonnafé, L.; TORT, P., L'Homme, cet inconnu?, París, Syllepse, 1992. - DARwin, Ch., L'Origine des espèces au moyen de la sélection naturelle, Verviers, Marabout-Université, 1973 (traducción de Moulinië, J.-J., publicada en Reinwald en 1873 a partir de las $5^{\text {a }}$ y $6^{\text {a }}$ ediciones inglesas); DARWIN, Ch., La Descendance de l'Homme et la sélection sexuelle (re- 
producción fotográfica de la traducción aparecida en 1881 en Reinwald, y debida a Edmond BARBIER, de la segunda edición inglesa revisada y aumentada por el autor), Bruselas, 1981, esencialmente los capítulos IV, V y XXI. [Esta reproducción conserva evidentemente todas las faltas del original, principalmente en el índice. El prólogo añadido en cabeza es un ejemplo entre otros de los contrasentidos corrientes unidos al desconocimiento de la obra y a las presiones ideológicas cuya operación ya hemos analizado]; DARwIN, Ch., La Filiation de l'Homme et la sélection liée au sexe, París, Syllepse, 1999, 826 p. Precedido de ToRT, P., «L'antropologie inattendue de Charles Darwin». Primer volumen aparecido (tomo 22) de las Obras completas de Darwin. Darwin, Ch., Autobiographie, traducción de Goux, J.-M., París, Belin, 1985.- Denton, M., Évolution, une théorie en crise, París, Flammarion, 1992 [1985].- ENGELS, F., Anti-Dühring, París, Éditions sociales, 1977 [1873]; EngELs, F., Dialectique de la nature, París, Éditions sociales, 1968 [1875]. - GALTON, F., «Hereditary Talent and Character», MacMillan's Magazine, junio y agosto de 1865; Galton, F., Hereditary Genius, Londres, MacMillan, 1869.- HAECKEL, E., Anthropogenie, Leipzig, W. Engelmann, 1874; E. HAECKEL, Die Lebenswunder, Stuttgart, A. Kröner, 1904. - MARX, K.; ENGELS, F., Lettres sur les sciences de la nature, París, Éditions sociales, 1973. - MiVART, S.G.J., Genesis of Species, Londres, MacMillan, 1871; MivART, S.G.J., Lessons from Nature, Londres, J. Murray, 1876. SPENCER, H., First Principles, 1862; Principles of Biology, 1864- 1867, 2 vol.; Principles of Sociology, 1876-1896, 3 vol..; Principles of Ethics, 1879-1893, 2 vol.; Essays, 1857-1874, 3 vol.; Autobiographie ( «naissance de l'évolutionisme libéral»), prologado por «Spencer et le système des sciences», por TORT, P., París, PUF, 1987; TORT, P., La Pensée hiérarchique et l'évolution, París, Aubier, 1983, pag. 165-197 («L'effet réversif et sa logique»), y el capítulo sobre Spencer; TORT, P. (dir.), Misère de la sociobiologie, París, PUF, 1985; TORT, P. (dir.), Darwinisme et société, París, PUF, 1992 (particularmente las dos primeras conferencias); TORT, P., «Nouveaux fondements pour une éthique évolutive», Diogène, $\mathrm{n}^{\circ} 172$, diciembre de 1995; Tort, P. (dir.), Dictionnaire du darwinisme et de l'évolution, París, PUF, 1996, 3 vol., 5000 pag., artículos: Altruisme (G. Guille-Escuret) y Addition (J. Gervet), Anthropologie darwinienne (P.T.), Aprendizaje (P.T.), Civilización (P.T.), Compensación - Tecnologías de (P.T.), Cruzamientos (P.T.), Darwinismo anglosajón (M. Di Gregorio); Darwinismo y evolucionismo filosófico (P.T.), Darwinismo social (D. Becquemont). Domesticación (P.T.), Efecto reversivo de la evolución (P.T.), Eugenismo (D. Becquemont ), Evolución - Sistema de la (P.T.), Haeckel (B. Rupp-Eisenreich), Galton (Ch. Lenay), Hunt (B. Rupp-Eisenreich), Instintos domésticos (P.T.), Instintos sociales (P.T.), Malthus (J. Dûpaquier) y Adición (P.T.), Marx-Engels y Darwin (B. Naccache), Organicismo sociológico (P.T.), Progreso (P.T.), Sociobiología (G. Guille-Escuret), Naturaleza/ Cultura (Y. Quiniou ) y Adición (P.T.), Selección artificial (P.T.), Selección inconsciente (P.T.), Selección natural (P.T.), Spencer (P.T.), Supervivencia del más apto (D. Becquemont), Simpatía (P.T.), Vacher de Lapouge (A. Béjin); TORT, P., «Sur le matérialisme darwinien en éthique», L' Inactuel, primavera 1996; TORT, P., «Le Dictionnaire du darwinisme ou les raisons d' une encyclopédie», Gradhiva, primavera 1996; TORT, P., Spencer et l'évolutionnisme philosophique, París, PUF, «Que sais-je?», 1996; TORT, P., Darwin et le darwinisme, París, PUF, «Quadrige», 1997; ToRT, P. (dir.), Pour Darwin (dir.), París, PUF, 1997; TORT, P., Darwin y el darwinismo, Madrid, Alianza Ed. (en preparación). 